IF. Sér. Reg. n. 54 p. $35-43$ maio 2016

http://dx.doi.org/10.4322/ifsr.2016.003

ISSN on-line 2179-2372

\title{
O MARCO LEGAL DA CIÊNCIA, TECNOLOGIA E INOVAÇÃO: A COMUNIDADE DE PESQUISA E A APROPRIAÇÃO PRIVADA DOS RECURSOS PÚBLICOS ${ }^{1}$
}

\section{THE LEGAL FRAMEWORK OF SCIENCE, TECHNOLOGY AND INNOVATION: RESEARCH COMMUNITY AND PRIVATE OWNERSHIP OF PUBLIC RESOURCES}

\author{
Rogério Bezerra da SILVA²
}

\begin{abstract}
RESUMO - Foi feita uma análise sobre o Marco Legal da Ciência, Tecnologia e Inovação (Lei Federal no 13.243/16). Apresenta-se algumas evidências de que o Marco Legal permite que Organizações Sociais - OSs se tornem as instituições responsáveis pelas pesquisas desenvolvidas no Brasil. É demonstrado que os membros da comunidade de pesquisa, especialmente os "acadêmicos empreendedores", são os interessados e que também serão estes os responsáveis pela criação dessas OSs.
\end{abstract}

Palavras-chave: Lei Federal nº 13.243/16; acadêmicos empreendedores; políticas públicas.

\begin{abstract}
An analysis of the Legal Framework of Science, Technology and Innovation (Federal Law n. 13,243/16) was made. It presents some evidence that the Legal Framework allows Social Organizations - OSs to become the institutions responsible for research developed in Brazil. It is shown that the members of the research community, especially the "academic entrepreneurs" are concerned and also will be those responsible for the creation of these OSs .
\end{abstract}

Keywords: Federal Law no. 13.243/16; academic entrepreneurs; public policy.

\section{INTRODUÇÃO}

Este artigo analisa o processo de elaboração da Lei Federal no 13.243, de 11 de janeiro de 2016, mais conhecida como Marco Legal da Ciência, Tecnologia e Inovação. Seu objetivo é apresentar algumas evidências de que a Lei vai fazer com que as Organizações Sociais - OSs se tornem as instituições responsáveis pelas pesquisas desenvolvidas no Brasil, o que vai levar à transferência para o setor privado dos recursos públicos investidos em Ciência e Tecnologia. Aliado a isto, serão também os membros da comunidade de pesquisa, especialmente os "acadêmicos empreendedores" (Dagnino, 2007), os responsáveis e interessados pela criação dessas OSs.

O Marco Legal tende a promover a transferência das atividades de pesquisa para a iniciativa privada, cujos "acadêmicos empreendedores" se transmudarão em empresários de modo a se apropriarem de uma maior parcela dos cerca de $1 \%$ do PIB brasileiro que é, anualmente, investido em Pesquisa e Desenvolvimento - P\&D.

O texto está dividido em cinco tópicos, além desta introdução. O tópico 2 apresenta as emendas presentes no Projeto de Lei da Câmara - PLC n ${ }^{\circ} 77 / 15$ que deu origem à Lei Federal n ${ }^{\circ}$ 13.243/16. No tópico 3, são apresentados os atores que participaram da elaboração do Marco Legal. No tópico 4, se faz uma avaliação da tomada de decisão sobre o Marco Legal. Por fim, o tópico 5 é a conclusão. Nelas são destacadas cinco consequências fundamentais para o Complexo Público de Ensino Superior e de Pesquisa com a sanção da Lei. 


\section{O QUE DIZ O MARCO LEGAL DA CIÊNCIA, TECNOLOGIA E INOVAÇÃO}

Em 31 de agosto de 2011, foi protocolado na Câmara Federal o Projeto de Lei $\mathrm{n}^{0} 2.177$ que instituía o então denominado "Código Nacional de Ciência, Tecnologia e Inovação" (Projeto de Lei n 2.177/11). O Projeto de Lei - PL recebeu a assinatura de todos os deputados membros da Comissão de Ciência e Tecnologia, Comunicação e Informática - CCTCI da Câmara dos Deputados, representantes do PSDB, PSB, PT, PR, PDT, PMDB e PPS, o que indica que houve consenso na apresentação do Projeto de Lei.

No mesmo ano, foi constituída uma Comissão Especial da Câmara (composta pelas Comissões de Educação e Cultura; de Trabalho, Administração e Serviço Público; de Ciência e Tecnologia, Comunicação e Informática; de Finanças e Tributação e de Constituição e Justiça e de Cidadania) para dar celeridade ao trâmite do processo, para a qual foi indicado um Relator, membro da Comissão.

Em 2015, no dia 9 de julho, foi apresentada a Redação Final do PL n ${ }^{\circ} 2.177 / 11$, com as emendas propostas por parlamentares e em Audiências Públicas (Tabela 1). O PL tem sua ementa mudada e passa, então, a dispor sobre

estímulos ao desenvolvimento científico, à pesquisa, à capacitação científica e tecnológica e à inovação, nos termos da Emenda Constitucional n ${ }^{\circ} 85$, de 26 de fevereiro de 2015; e altera as Leis, $\mathrm{n}^{\mathrm{o}} 6.815$, de 19 de agosto de $1980, \mathrm{n}^{\circ} 8.010$, de 29 de março de $1990, \mathrm{n}^{\circ} 8.032$, de 12 de abril de 1990, no 8.666 , de 21 de junho de 1993, no 8.745, de 9 de dezembro de 1993, $\mathrm{n}^{\circ} 8.958$, de 20 de dezembro de 1994, no 10.973, de 2 de dezembro de 2004, $\mathrm{n}^{\circ} 12.462$, de 4 de agosto de 2011 e $\mathrm{n}^{\mathrm{o}} 12.772$ de 28 de dezembro de 2012.

Quadro 1. Emendas a leis propostas pelo PLC $\mathrm{n}^{\circ} 77 / 15$.

Table 1. Amendments to laws proposed by the PLC no. 77/15.

Lei ${ }^{\circ} 6.815$, de 1980 (Estatuto do Estrangeiro)

Lei no 8.010, de 1990 (Lei de Importações de Bens Destinados à Pesquisa)

Lei n ${ }^{\circ}$ 8.032, de 1990 (Lei de Isenção ou Redução de Impostos de Importação)

Lei no 8.666, de 1993 (Lei das Licitações e Contratos da Administração Pública)

Lei no 8.745, de 1993 (Lei de Contratações Temporárias)

Lei $n^{\circ}$ 8.958, de 1994 (Lei das Relações entre as Instituições Federais de Ensino Superior e de Pesquisa Científica e Tecnológica e as Fundações de Apoio)

Lei no 10.973, de 2004 (Lei de Inovação)

Lei no 12.462, de 2011 (Lei do Regime Diferenciado de Contratações Públicas)

Lei $\mathrm{n}^{\circ}$ 12.772, de 2012 (Lei da Estruturação do Plano de Carreiras e Cargos do Magistério e da Contratação de Professores Substitutos, Visitantes e Estrangeiros)

Aprovado pela Câmara, o Projeto de Lei foi então enviado ao Senado em 16 de julho de 2015, onde adquiriu a identificação PLC $n^{\circ} 77 / 15$. No Senado, contou com a Relatoria de um senador indicado pela Comissão de Constituição, Justiça e Cidadania.

O Projeto de Lei constituiu-se, como observado na Tabela 1, em uma proposta de emenda a diversas leis que versam sobre ciência e tecnologia. Ocorreu, inclusive, durante o trâmite do Projeto de Lei na Câmara, a promulgação da Emenda Constitucional nº 85, de 2015.

A Constituição Federal, com a Emenda Constitucional em vigor, em seu art. 219-B torna legal a cooperação entre a União, Estados, Distrito Federal e Municípios com entidades privadas. O Art. 219-A estabelece os termos dessa cooperação, que pode ser, inclusive, com "compartilhamento de recursos humanos especializados e capacidade instalada" e "mediante contrapartida financeira ou não financeira assumida pelo ente beneficiário". 
Ao se analisar essa legislação observa-se que, quanto aos recursos humanos provenientes de Instituições Públicas de Pesquisa: i) os pesquisadores poderão atuar dentro das empresas, caso essas tenham capacidade de pesquisa instalada, ou ii) os pesquisadores poderão atuar nas próprias instituições públicas de pesquisa em favor das empresas. No que diz respeito aos recursos financeiros: i) as empresas podem financiar parcial ou totalmente a pesquisa desenvolvida em sua própria instituição ou em uma instituição pública, ou ii) as empresas podem oferecer qualquer outro tipo de contrapartida e ter acesso a recursos públicos para financiar suas pesquisas.

Das cerca de 200 emendas (modificativas, aditivas ou supressivas) propostas no PLC $\mathrm{n}^{\circ}$ 77/15 às leis em vigor, cerca de $80 \%$ foram em relação à Lei de Inovação. As emendas a essa Lei, sancionadas com a publicação do Marco Legal, são aqui classificadas em cinco categorias:

i) emendas voltadas à transferência para a iniciativa privada das atividades públicas de pesquisa;

ii) emendas voltadas à disseminação de arranjos produtivos científicos e tecnológicos;

iii) emendas voltadas à internacionalização da pesquisa brasileira;

iv) emendas voltadas a tornar o Estado investidor de capital de risco, e

v) emendas voltadas a alocar recursos de pessoal, pagos com dinheiro público, em entes privados.

\subsection{Emendas Voltadas à Transferência para a Iniciativa Privada das Atividades Públicas de Pesquisa}

Essas emendas são assim classificadas haja vista que é isso o que tende a ocorrer com as instituições e com o desenvolvimento de pesquisa no País:

Art. $9^{\circ}$ É facultado à ICT celebrar acordos de parceria com instituições públicas e privadas para realização de atividades conjuntas de pesquisa científica e tecnológica e de desenvolvimento de tecnologia, produto, serviço ou processo.

$\S 1^{\circ} \mathrm{O}$ servidor, o militar, o empregado da ICT pública e o aluno de curso técnico, de graduação ou de pós-graduação envolvidos na execução das atividades previstas no caput poderão receber bolsa de estímulo à inovação diretamente da ICT a que estejam vinculados, de fundação de apoio ou de agência de fomento.

Art. $9^{\circ}$-A. Os órgãos e entidades da União, dos Estados, do Distrito Federal e dos Municípios são autorizados a conceder recursos para a execução de projetos de pesquisa, desenvolvimento e inovação às ICTs ou diretamente aos pesquisadores a elas vinculados, por termo de outorga, convênio, contrato ou instrumento jurídico assemelhado.

E, como definiu o Marco Legal da Ciência, Tecnologia e Inovação, ICTs são:

Art. $2^{\circ}[\ldots]$

V - Instituição Científica, Tecnológica e de Inovação (ICT): órgão ou entidade da administração pública direta ou indireta ou pessoa jurídica de direito privado sem fins lucrativos legalmente constituída sob as leis brasileiras, com sede e foro no País, que inclua em sua missão institucional ou em seu objetivo social ou estatutário a pesquisa básica ou aplicada de caráter científico ou tecnológico ou o desenvolvimento de novos produtos, serviços ou processos;

Ou seja, o Marco Legal permite a criação de ICTs com estatuto jurídico de Organizações Sociais - OSs para o desenvolvimento de atividades de pesquisa no Brasil. E as ICTs, constituídas como OSs, poderão: i) receber recursos públicos de todos os entes federados e fundações de apoio para a cobertura de todas as suas despesas e ii) receber recursos de pessoal (pesquisadores) pagos com recursos públicos. 


\title{
2.2 Emendas Voltadas à Disseminação de Arranjos Produtivos Científicos e Tecnológicos
}

Além da disseminação de ICTs, outras importantes emendas são aquelas "voltadas à disseminação de arranjos produtivos científicos e tecnológicos", conforme se pode observar no Art. $3^{\circ}$-B:

\begin{abstract}
Art. $3^{\circ}$-B. A União, os Estados, o Distrito Federal, os Municípios, as respectivas agências de fomento e as ICTs poderão apoiar a criação, a implantação e a consolidação de ambientes promotores da inovação, incluídos parques e polos tecnológicos e incubadoras de empresas, como forma de incentivar o desenvolvimento tecnológico, o aumento da competitividade e a interação entre as empresas e as ICTs.

[...]

$\S 2^{\circ}$ Para os fins previstos no caput, a União, os Estados, o Distrito Federal, os Municípios, as respectivas agências de fomento e as ICTs públicas poderão:

I - ceder o uso de imóveis para a instalação e a consolidação de ambientes promotores da inovação, diretamente às empresas e às ICTs interessadas ou por meio de entidade com ou sem fins lucrativos que tenha por missão institucional a gestão de parques e polos tecnológicos e de incubadora de empresas, mediante contrapartida obrigatória, financeira ou não financeira, na forma de regulamento;
\end{abstract}

Com o Marco Legal, espaços e prédios públicos poderão ser cedidos a entes privados, como empresas e Organizações Sociais (as ICTs), para a construção de arranjos produtivos.

\subsection{Emendas Voltadas à Internacionalização da Pesquisa Brasileira}

Outras emendas importantes são aquelas "voltadas à internacionalização da pesquisa brasileira":

Art. $3^{\circ}$-C. A União, os Estados, o Distrito Federal e os Municípios estimularão a atração de centros de pesquisa e desenvolvimento de empresas estrangeiras, promovendo sua interação com ICTs e empresas brasileiras e oferecendo-lhes o acesso aos instrumentos de fomento, visando ao adensamento do processo de inovação no País.

Como observado, o Marco Legal prevê a atração de centros de pesquisa de empresas estrangeiras e, para isto, permite que eles tenham acesso a recursos públicos nacionais.

\subsection{Emendas Voltadas a Tornar o Estado Investidor de Capital de Risco}

Há também as "emendas voltadas a tornar o Estado investidor de capital de risco":

Art. $5^{\circ}$ São a União e os demais entes federativos e suas entidades autorizados, nos termos de regulamento, a participar minoritariamente do capital social de empresas, com o propósito de desenvolver produtos ou processos inovadores que estejam de acordo com as diretrizes e prioridades definidas nas políticas de ciência, tecnologia, inovação e de desenvolvimento industrial de cada esfera de governo.

Os entes federados ficam autorizados a participar do capital social de empresas. Constitui-se, desse modo, uma forma legal de as empresas conseguirem recursos públicos para investir em seus processos e produtos com potencial inovador.

\subsection{Emendas voltadas a alocar recursos de pessoal, pagos com dinheiro público, em entes privados:} entes privados".

Há também as "emendas voltadas a alocar recursos de pessoal, pagos com dinheiro público em

Art. $14[\ldots]$

$\S 3^{\circ}$ As gratificações específicas do pesquisador público em regime de dedicação exclusiva, inclusive aquele enquadrado em plano de carreiras e cargos de magistério, serão garantidas, na forma do $\S 2^{\circ}$ deste artigo, quando houver o completo afastamento de ICT pública para outra ICT, desde que seja de conveniência da ICT de origem.

Art. 14-A. O pesquisador público em regime de dedicação exclusiva, inclusive aquele enquadrado em plano de carreiras e cargos de magistério, poderá exercer atividade remunerada de pesquisa, desenvolvimento e inovação em ICT ou em empresa e participar da execução de projeto aprovado ou custeado com recursos previstos nesta Lei, desde que observada a conveniência do órgão de origem e assegurada a continuidade de suas atividades de ensino ou pesquisa nesse órgão, a depender de sua respectiva natureza. 
Pesquisador público em regime de dedicação exclusiva, inclusive aquele enquadrado em planos de carreiras e cargos de magistério, poderá afastar-se de suas instituições de origem para prestar serviços em ICTs públicas ou privadas e mesmo nas empresas, mantendo suas gratificações e acrescê-las com ganhos vindos destas novas atividades.

São essas emendas à Lei de Inovação que tendem a levar a uma maior transformação no que pode ser denominado Complexo Público de Ensino Superior e de Pesquisa (Dagnino, 2007), uma vez que disseminariam as Instituições Científicas, Tecnológicas e de Inovações - ICTs, que seriam os órgãos ou entidade da administração pública direta ou indireta, ou pessoa jurídica de direito privado sem fins lucrativos, e centralizariam nelas os recursos financeiros e de pessoal para o desenvolvimento de pesquisa no País. Isso, em detrimento da expansão das instituições públicas estatais.

\section{QUEM PARTICIPOU DA ELABORAÇÃO DO MARCO LEGAL}

A tramitação do PL $n^{\circ}$ 2.177/11, na Câmara dos Deputados, contou com a realização de Audiências Públicas, acompanhadas por Seminários e Grupo de Trabalho, de modo a contribuir com a redação do Projeto.

As 14 Audiências Públicas tiveram início mais de um ano após o Projeto protocolado e ocorreram entre abril e setembro de 2013 (Brasil, 2011), sendo:

-6 na região Centro-Oeste (todas em Brasília);

- 4 na região Sudeste (São Paulo, Rio de Janeiro, Vitória e em Belo Horizonte);

-2 na região Norte (Manaus e Porto Velho) e

- 2 na região Nordeste (ambas em Salvador).

Nessas Audiências Públicas, participaram como palestrantes, a Convite da Comissão Especial da Câmara Destinada a Proferir Parecer ao Projeto de Lei, 67 convidados. Destes:

- 33 pertenciam à comunidade de pesquisa (ou seja, são professores universitários ou pesquisadores ligados a instituições de pesquisa brasileiras), o que corresponde a cerca de $50 \%$ do total dos participantes convidados;

- 23 "políticos" (deputados, ministros ou secretários estaduais de ciência e tecnologia), quase 35\% do total;

- 5 "empresários" (representantes de entidades empresariais), o que corresponde a 7\% dos participantes;

- 7 do "quadro técnico administrativo do setor público" (técnicos de ministérios e de órgãos jurídicos), o que corresponde a $8 \%$ dos participantes.

Dentre a comunidade de pesquisa, as instituições que mais estiveram presentes nas Audiências Públicas, como participantes convidados para os seminários, foram:

- Fórum Nacional de Gestores de Inovação e Transferência de Tecnologia-FORTEC, em cinco seminários;

- Sociedade Brasileira para o Progresso da Ciência - SBPC, em quatro seminários;

- Universidade de São Paulo - USP, em quatro seminários;

- Fundação Oswaldo Cruz - FIOCRUZ, em três seminários;

- Conselho Nacional das Fundações Estaduais de Amparo à Pesquisa - CONFAP, Associação Nacional dos Dirigentes das Instituições Federais de Ensino Superior - ANDIFES, Associação Brasileira dos Reitores das Universidades Públicas, Estaduais e Municipais - ABRUEM e Associação Brasileira das Instituições de Pesquisa Tecnológica e Inovação - ABIPTI participaram, cada uma, de dois seminários.

O Relator da Comissão Especial foi o político presente em todas as Audiências Públicas. Além dele, também participaram apenas cinco deputados, cada um em uma Audiência distinta.

E, como destacado no Relatório da Comissão "em vista da complexidade da matéria e da diversidade de enfoques oferecidos pelos diversos convidados nas audiências públicas e seminários, este Relator, ouvida a Comissão Especial, optou por formar um grupo de trabalho que examinasse as várias contribuições” (Brasil, 2014, p. 30). 
Um Grupo de Trabalho para tratar das contribuições ao Projeto de Lei foi então formado, composto por 40 membros, entre eles:

- 20 membros pertenciam à comunidade de pesquisa (50\% dos membros do Grupo);

- 12 membros eram do "quadro técnico administrativo do setor público" (30\% do Grupo);

- 5 representantes das Forças Armadas (12,5\% do Grupo);

- 2 "empresários" ( $5 \%$ do Grupo) e

-1 "político" (2,5\% do Grupo).

Foi o Grupo de Trabalho que consolidou as propostas apresentadas como emendas ao PL $\mathrm{n}^{\circ}$ 2.177/11 que, posteriormente, foi aprovado pela Câmara dos Deputados e enviado para a apreciação do Senado.

No Senado, em 17 de novembro de 2015, as Comissões de Assuntos Econômicos e de Ciência, Tecnologia, Inovação, Comunicação e Informática aprovaram requerimento de realização de Audiência Pública conjunta com a finalidade de instruir o PLC no 77/15. Essa Audiência ocorreu no dia 18 de novembro do mesmo ano (um dia após sua aprovação) e contou com os seminários de:

- 4 membros da comunidade de pesquisa (FORTEC, CONFAP, CONFIES e UNB);

- 1 "empresário" (Confederação Nacional das Indústrias - CNI).

Como observado, é a comunidade de pesquisa o ator dominante no processo de formulação do Marco Legal da Ciência, Tecnologia e Inovação. E, embora o Marco Legal favoreça a apropriação privada dos recursos públicos (financeiros e de pessoal) a serem aplicados em ciência e tecnologia no Brasil, os "empresários" tiveram pouca participação na formulação da proposta.

\section{UMA AVALIAÇÃO DA TOMADA DE DECISÃO SOBRE O MARCO LEGAL}

Os resumos das Audiências Públicas realizadas durante o processo de tramitação do PL na Câmara Federal destacam as falas de alguns dos palestrantes convidados para os Seminários, membros da comunidade de pesquisa. A situação-problema que o PL visa resolver pode ser definida como: debilidade da interação entre o potencial de $\mathrm{P} \& \mathrm{D}$ com os setores produtivos brasileiros.

Como pode ser observado nas figuras 1 e 2, a debilidade daquela interação estaria refletida no contínuo aumento do dispêndio em P\&D no Brasil, mas que não levou a um aumento da taxa de inovação brasileira.

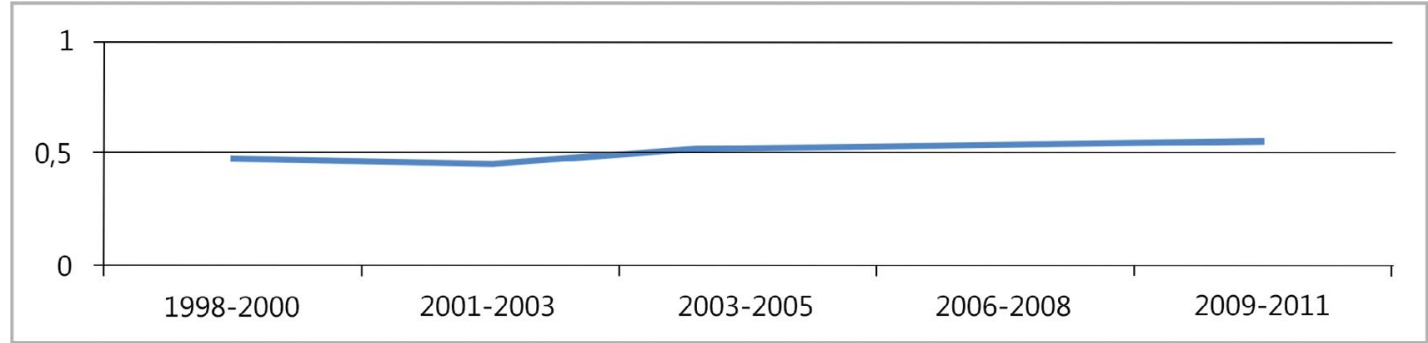

Figura 1. Dispêndio em P\&D nos períodos (P\&D/PIB). Fonte: Instituto Brasileiro de Geografia e Estatística - IBGE $(2000 ; 2003 ; 2005 ; 2008 ; 2011)$.

Figure 1. Expenditure on P\&D in the period (P\&D/PIB). Source: Instituto Brasileiro de Geografia e Estatística - IBGE $(2000 ; 2003 ; 2005 ; 2008 ; 2011)$.

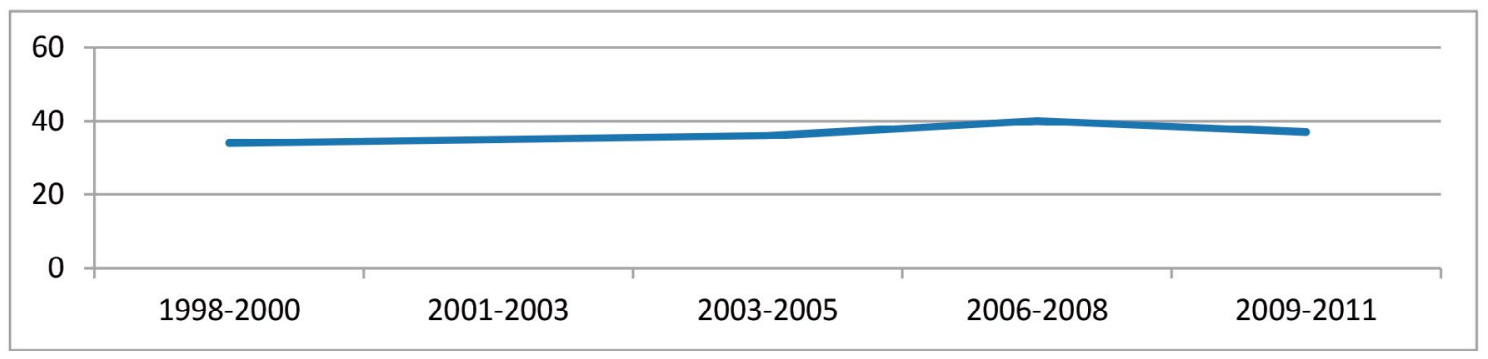

Figura 2. Taxa de inovação da indústria brasileira nos períodos (em \%). Fonte: IBGE (2000; 2003; 2005; 2008; 2011).

Figure 2. Brazilian industry innovation rate in the period (in\%). Source: IBGE $(2000 ; 2003 ; 2005 ; 2008 ; 2011)$. 
SILVA, R. B. et al. O Marco Legal da Ciência, Tecnologia e Inovação.

Apesar do aumento do dispêndio em P\&D entre os períodos, a taxa de inovação manteve-se constante entre 1998-2000 e 2003-2005, com um leve aumento entre 2006-2008, mas com tendência à queda no período mais recente (2009-2011), como observado na Figura 2.

Até mesmo porque, quando se trata de acesso a recursos públicos para atividades de inovação, são os programas voltados à aquisição de máquinas e equipamentos os mais acessados pelas indústrias, como observado na Figura 3.

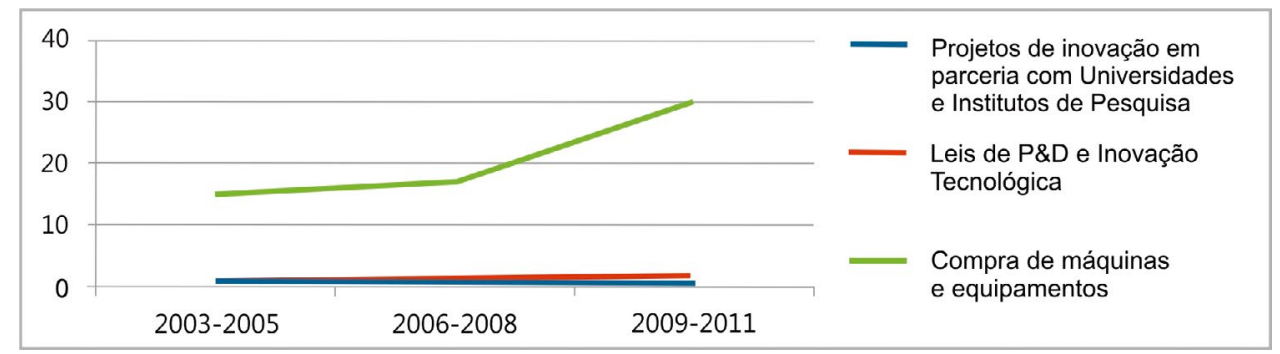

Figura 3. Percentual das indústrias inovadoras que utilizaram programas do governo (em \%). Fonte: IBGE $(2000 ; 2003 ; 2005$; 2008; 2011).

Figure 3. Percentage of innovative industries that used government programs (in \%). Source:IBGE (2000; 2003; 2005; 2008; 2011).

Como também demonstrado pela Figura 4, são pouco importantes para as indústrias brasileiras as atividades de P\&D.

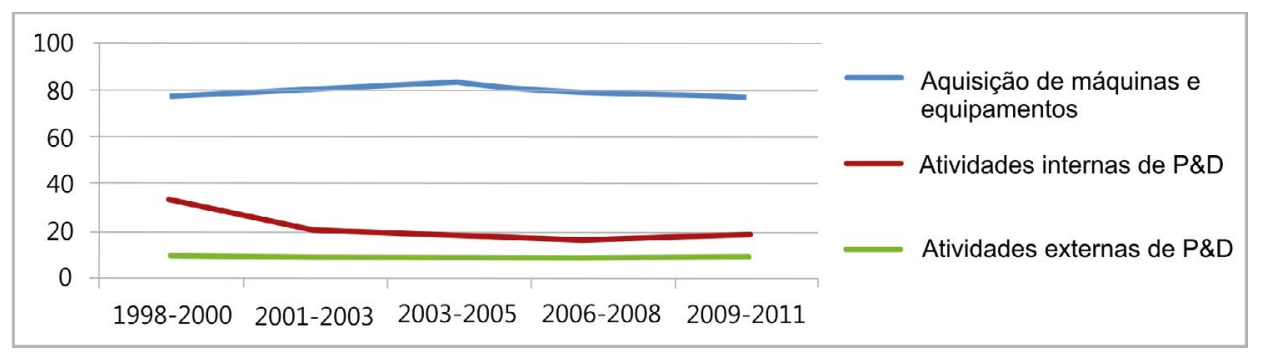

Figura 4. Importância das atividades inovativas nos períodos (em \%). Fonte: IBGE (2000; 2003; 2005; 2008; 2011).

Figure 4. Importance of innovative activities in the periods (in \%). Source: IBGE (2000; 2003; 2005; 2008; 2011).

Como observado na Figura 4, a atividade inovativa mais relevante para as indústrias é a aquisição de máquinas e equipamentos. Apesar de esta atividade possuir leve tendência de queda no período atual, ela continua tendo cerca de $75 \%$ de relevância para as indústrias, ao passo que a aquisição interna de P\&D é cerca de $15 \%$ relevante, e a externa, cerca de 10\%, no período de 2009-2011.

Além das atividades (interna e externa) de P\&D, a parceria com universidades e institutos de pesquisa também é pouco relevante para as indústrias em suas estratégias inovativas (Figura 5).

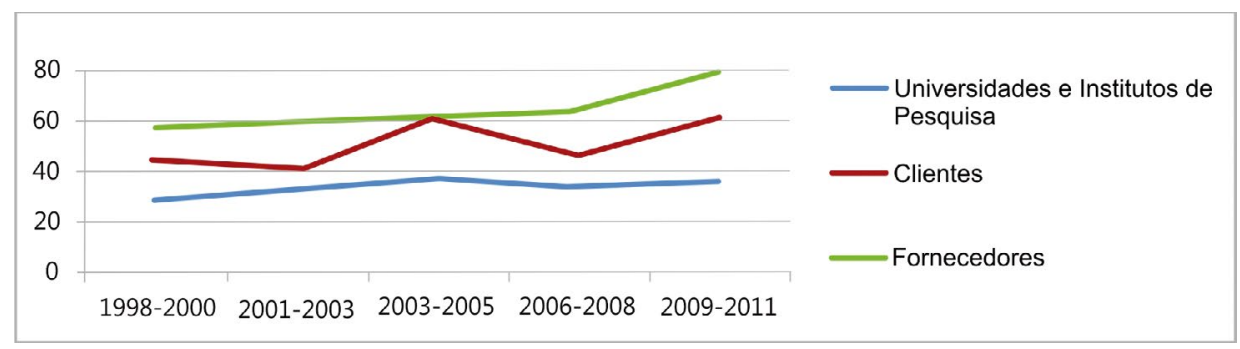

Figura 5. Importância atribuída pela indústria aos parceiros de cooperação (em \%). Fonte: IBGE (2000; 2003; 2005; 2008; 2011). Figure 5. Importance given by the industry to the cooperation partners (in \%). Source: IBGE (2000; 2003; 2005; 2008; 2011). 
Para as indústrias, as Universidades e Institutos de Pesquisa têm uma relevância de cerca de $30 \%$ entre os períodos, ao passo que os fornecedores e clientes vêm adquirindo crescente relevância, saindo de $55 \%$ e $45 \%$, respectivamente, no período $1998-2000$, para cerca de $75 \%$ e $60 \%$ no período $2009-2011$.

A Figura 6 também demonstra o quanto a interação com Universidades e Institutos de Pesquisa é pouco importante para as estratégias inovativas das indústrias.

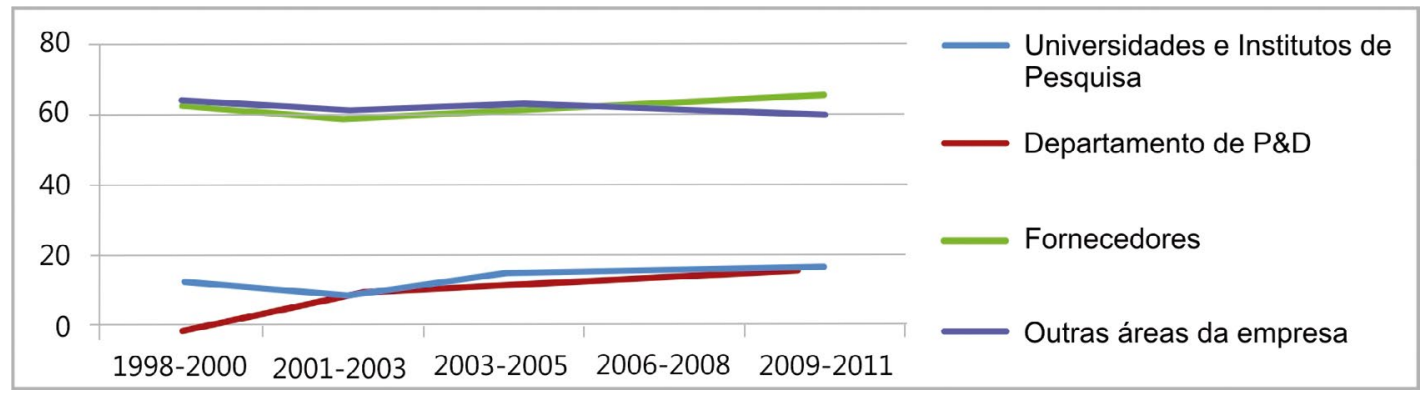

Figura 6. Importância atribuída pela indústria às fontes de informação para inovação (em \%). Fonte: IBGE (2000; 2003; 2005; 2008; 2011).

Figure 6. Importance given by the industry to information sources for innovation (in \%). Source: IBGE (2000; 2003; 2005; 2008; 2011).

Apesar da leve tendência de aumento da importância das Universidades e Institutos de Pesquisa ao longo dos períodos, os fornecedores são os mais relevantes e seguem com tendência de aumento. A Figura 6 também apresenta uma tendência de que os departamentos de P\&D (internos às empresas) superarão a importância das Universidades e Institutos de Pesquisa nos próximos anos.

Então, como demonstram os dados, a debilidade da interação entre o potencial de P\&D com os setores produtivos brasileiros é uma situação-problema percebida pelo ator dominante no processo de tomada de decisão da política pública, não necessariamente ela condiz com as necessidades das empresas e as trajetórias de inovação adotadas pelas mesmas.

\section{CONCLUSÃO}

Com a aprovação do Marco Legal da Ciência, Tecnologia e Inovação, Lei Federal n ${ }^{\circ}$ 13.243/16, as principais mudanças que tendem a ocorrer no Complexo Público de Ensino Superior e de Pesquisa brasileiro são:

i) a substituição de instituições públicas (estatais) de pesquisa por Organizações Sociais - OSs. Seria a continuação da Reforma do Estado proposta nos anos 1990, em que se preconizava que a oferta de serviços sociais e científicos deveria ser feita por OSs, cuja propriedade seria considerada pública não estatal (BresserPereira, 2008);

ii) professores universitários e pesquisadores das instituições públicas (estatais) poderão acumular os rendimentos de suas atividades no setor público e também os provenientes de suas atividades desenvolvidas nas OSs;

iii) com essas OSs, professores e pesquisadores poderão atuar dentro das empresas, tanto as de pequeno quanto as de grande porte. Isso tende a levar a um aumento da importância atribuída pelas empresas à $\mathrm{P} \& \mathrm{D}$ como estratégia inovativa. Isso porque essas OSs, com acesso a recursos públicos (financeiros, de pessoal e imóvel), vão desenvolver atividades de pesquisa internas às empresas;

iv)o gasto em P\&D, no Brasil, vai continuar o mesmo ou tende a decair. Isso porque o Estado inclina-se a manter ou ampliar seus gastos, ao passo que as empresas tendem a diminuir seus gastos, haja vista que elas poderão ter acesso facilitado a todos os recursos (financeiros e de pessoas) oferecidos pelo Estado;

v) o número de patentes registradas pelas Universidades tenderá a cair, pois o registro passará a ser feito em nome dos pesquisadores envolvidos no processo e das OSs a que eles estarão ligados. A fonte dos recursos financeiros para a manutenção dos registros continuará a mesma, ou seja, os cofres públicos. 
SILVA, R. B. et al. O Marco Legal da Ciência, Tecnologia e Inovação.

Finalmente, cumpre salientar uma vez mais que é a própria comunidade de pesquisa, em especial seus "acadêmicos empreendedores", que vem atuando no Congresso brasileiro para que seja implementado um código legal que, mais que às empresas, beneficie aqueles professores universitários e pesquisadores que, de algum modo, querem efetivar suas próprias empresas ou aqueles que desenvolvem algum produto ou processo e querem explorá-lo economicamente.

\section{REFERÊNCIAS BIBLIOGRÁFICAS}

BRASIL. Relatório da Comissão Especial destinada a proferir parecer ao Projeto de Lei $\mathrm{n}^{\mathrm{o}}$ 2.177, de 2011, do sr. Bruno Araújo, que "Institui o Código Nacional de Ciência, Tecnologia e Inovação". (PL 2177/11). Disponível em: <http://www2.camara.leg.br/proposicoesWeb/prop_mostrarintegra?codteor=1240923\& filename $=$ PRL $+2+P L 217711+\% 3 \mathrm{D} \% 3 \mathrm{E}+\mathrm{PL}+2177 / 2011>$. Acesso em: 15 fev. 2016.

PLC $\mathrm{n}^{\circ}$ 77/15. Dispõe sobre estímulos ao desenvolvimento científico, à pesquisa, à capacitação científica e tecnológica e à inovação, nos termos da Emenda Constitucional $\mathrm{n}^{\circ}$ 85, de 26 de fevereiro de 2015; e altera as Leis $\mathrm{n}^{\circ} \mathrm{s}$ 10.973, de 2 de dezembro de 2004, 6.815, de 19 de agosto de 1980, 8.666, de 21 de junho de 1993, 12.462, de 4 de agosto de 2011, 8.745, de 9 de dezembro de 1993, 8.958, de 20 de dezembro de 1994, 8.010, de 29 de março de 1990, 8.032, de 12 de abril de 1990, e 12.772, de 28 de dezembro de 2012. Disponível em: <http://www25.senado.leg.br/ web/atividade/materias/-/materia/122406>. Acesso em: 16 fev. 2016.

BRESSER-PREIRA, L.C. O modelo estrutural de gerência pública. Revista de Administração Pública, n. 42 , v. 2, p. 391-410, mar./abr. 2008.

DAGNINO, R. Ciência e tecnologia no Brasil: o processo decisório e a comunidade de pesquisa. Campinas: UNICAMP, 2007. 215 p.

INSTITUTO BRASILEIRO DE GEOGRAFIA E ESTATÍSTICA - IBGE. Pesquisa de Inovação Tecnológica

- PINTEC. 2000. Disponível em: < http://www.ibge.gov.br/home/estatistica/pesquisas/pesquisa_resultados. php?id_pesquisa=33>. Acesso em: 16 fev. 2016.

2003. Disponível em: <http://www.ibge.gov.br/home/estatistica/economia/industria/pintec/ $\overline{2003 / \text { default.shtm }}$. Acesso em: 16 fev. 2016.

.2005. Disponível em: <http://www.ibge.gov.br/home/estatistica/economia/industria/pintec/ 2005/default.shtm>. Acesso em 16 fev. 2016.

. 2008. Disponível em: <http://www.ibge.gov.br/home/estatistica/economia/industria/pintec/ 2008/default.shtm>. Acesso em: 16 fev. 2016.

2011. Disponível em: $<\mathrm{http}: / / w w w . i b g e . g o v \cdot b r / h o m e / e s t a t i s t i c a / e c o n o m i a / i n d u s t r i a / p i n t e c /$

2011/default.shtm>. Acesso em: 16 fev. 2016. 